\title{
Umbrales biológicos de la modernidad política en Michel Foucault*
}

\author{
Biological thresholds of modern politics in Michel Foucault
}

EMILIANO SACCHI**

\begin{abstract}
Resumen: Genealógicamente la Vida se constituyó en dominio por conocer (Biología) como resultado de unas relaciones de poder que la instituyeron como objeto posible a partir de la larga historia del gobierno de la grey, de su salvación, de la disciplina del cuerpo, etc. (Foucault, 1978). Pero para poder hacer de la vida un objeto de la (bio)política, fue necesario un saber capaz de sitiarla e inmovilizarla. En este artículo recurrimos a la arqueología del saber foucaultiana para reconstruir sobre su trasfondo y en relación al poder disciplinario una serie umbrales a partir de los cuales se definieron los rasgos paradigmáticos de la biopolítica moderna.
\end{abstract}

Palabras clave: Biopolítica, biología, poder disciplinario, cuerpo, episteme.

\begin{abstract}
Genealogically Life becomes an object of knowledge (Biology) as a result of power relations in the long history of the government of the flock, of salvation, of the body discipline, etc. But to make life an object of the (bio) politics, it was necessary a kind of knowledge able to fix and immobilize it. In this paper we use the foucauldian archeology of knowledge in order to reconstruct on their background and in relation to the disciplinary power a set of threshold that defines the paradigmatic features of modern biopolitics.
\end{abstract}

Keywords: Biopolitics, biology, body, disciplinary power, episteme.

\footnotetext{
"Se quieren hacer historias de la biología en el XVIII pero no se advierte que la biología no existía (...). Y si la biología era desconocida, lo era por una razón muy sencilla: la vida misma no existía” M. Foucault, Las palabras y las cosas (1966:28)
}

Fecha de recepción: 22/07/2014. Fecha de aceptación: 16/07/2015.

* Este trabajo se ha realizado en el marco de la investigación que el autor desarrolla con el apoyo del Consejo Nacional de Investigaciones Científicas y Técnicas de la Argentina y de la Secretaría de Ciencia y Técnica de la Universidad Nacional del Comahue.

** Emiliano Sacchi es Doctor en Ciencias Sociales por la Universidad de Buenos Aires, Profesor Adjunto de Teoría Política de la Universidad Nacional del Comahue (UNCo), Becario Posdoctoral del Consejo Nacional de Investigaciones Científicas y Técnicas (CONICET) y miembro del Centro de Estudios en Filosofía de la Cultura (CEFC). E-Mail: emiliano_sacchi@yahoo.com. Actualmente investiga las transformaciones de la biopolítica y de las formas de gubernamentalidad en las sociedades contemporáneas. Ha publicado numerosos artículos sobre estas temáticas, algunos de los cuales están citados en la bibliografía de este trabajo. 


\section{Una invención reciente}

Es conocido el gusto del filósofo francés por este tipo de negaciones: la Locura, la Sexualidad, el Estado, la Vida, el Hombre, etc. no existían. Y no en última instancia sino de modo concluyente: en tal momento histórico, en tal formación discursiva, etc. no existían. Pero qué persigue Foucault con tales aseveraciones, qué implica y sobre todo: ¿qué afirma? Sería ingenuo creer que se trata tan sólo de una negación, cuando se trata más bien "de un problema completamente inverso” (Foucault, 1994a:726). Esa declaración siempre polémica e irónica de inexistencia, suerte de sentencia, tiene otra función, mucho más positiva: mostrar en la historia, en los complejos mecanismos de saber y poder, en distintos juegos de verdad, la invención (Erfindung), la emergencia (Entstehung), el nacimiento (Gebürt) de cada una de esas figuras ${ }^{1}$. Ya en la Historia de la locura, se trataba de lo mismo, es decir, si se supone que la locura no existe, qué historia se puede hacer de esos diferentes acontecimientos, de toda esa serie de prácticas, de técnicas de saber, de esos mecanismos de poder que se ajustan y ajustan a esa cosa supuesta que es la locura (Foucault, 2004b:15; Veyne, 2008:15).

Pues bien, es en el marco de esa arqueología mucho más general de la modernidad que constituye Las palabras y las cosas, que Foucault (1966) deja caer esa declaración de inexistencia, esa puesta en suspenso, ni más ni menos que de la vida misma. Una vez más se trata de hacer lugar para preguntarse qué historia puede hacerse. Esa historia, según Foucault, es la historia de una serie de rupturas, pero sobre todo de la señalada por el nombre de G. Cuvier. Es a partir de ésta que puede pensarse modernamente la biología. Asumiendo el riesgo de esquematizar excesivamente, pude decirse que para la arqueología foucaultiana a partir de la anatomía comparada cuveriana (y en congruencia con la mirada anatomoclínica bichatiana), se dará una desarticulación entre la visión y el lenguaje que marcó el nacimiento de la biología moderna y que transformó, desde la profundidad de los cuerpos, todo el régimen de lo visible y lo enunciable (Foucault, 1963:177-244). A la vez, esta profundidad, se hizo posible un nuevo nivel ontológico emancipado de la representación, por lo que tanto los seres vivos como las relaciones entre identidad y diferencia y entre lo continuo y lo discontinuo en la naturaleza cambiaron completamente de estatuto. En el paso del movimiento continuo en la serie infinita de los seres (cadena natural, Armonía Universal) a la inmovilidad de los estratos geológicos, en el paso del despliegue en el espacio a la profundidad del tiempo, y en el paso de la manifestación visible al impulso interior, la vida se convertió en una fuerza fundamental que se sitúa más allá de las leyes generales del ser de la representación.

Del lado de los estratos de saber los índices enunciativos de esa transformación, las nociones que señalan sus confines, son según Foucault el organismo, la función, el medio y la población. Éstos definen una 'regularidad en la dispersión' de los enunciados científicos sobre la vida en la modernidad, constituyen el suelo a partir del cual es pensable modernamente la Vida. Si nos interesa reconstruir y comprender el sentido de la biopolítica tal cual la elaborara Foucault en los años 70, estos mojones son decisivos. En efecto, en la Voluntad de saber (Foucault, 1976:168) Foucault definía la extensión y la historia del basto campo del

1 Estas son las nociones bajo las que Foucault presenta el trabajo de la genealogía en F. Nietzsche y por oposición al relato del origen (Ursprung). 
poder sobre la vida (bio-poder) que se desarrolló desde el siglo XVII a partir de dos polos entrelazados pero a su vez claramente distinguibles. Al primero de esos polos Foucault lo llamará anátomo-política del cuerpo humano y al segundo biopolítica de las poblaciones. Ambos constituyen los dos polos del diagrama más general del Biopoder o la Biopolítica. Tecnologías políticas orientadas al individuo y a la multiplicidad ha habido en diferentes y heterogéneos diagramas de poder, pero lo que caracteriza a la biopolítica moderna es que el individuo y la multiplicidad son asidos a partir de ese nivel de lo real que es lo biológico. Las estrategias que se dirigen al cuerpo individual, lo que Foucault llama polo anátomopolítico se refieren, en tanto se centran en el cuerpo y tienden al aumento de sus aptitudes, al aprovechamiento de sus fuerzas, a la producción paralela y proporcional de la utilidad y docilidad de los cuerpos, a lo que Foucault había analizado en Vigilar y castigar de forma detallada como poder disciplinario (Foucault, 1975). El segundo polo, formado medio siglo más tarde, en la segunda mitad del siglo XVIII y cuya expansión se da en XIX, se centró ya no en el cuerpo (orgánico) individual sino en lo que Foucault primero llamará el cuerpoespecie y luego, de modo más decidido en el curso de 1978, la población (Foucault: 2004a), es decir: ese fenómeno que sirve de soporte a los procesos biológicos en tanto constituye una masa global investida de procesos de conjunto que son específicos de la vida, como el nacimiento, la muerte, la producción, la enfermedad, la longevidad, etc. procesos cuya regulación, aseguración y optimización tomará a su cargo la biopolítica de la población. Así, concluye Foucault: "las disciplinas del cuerpo y las regulaciones de la población constituyen los dos polos alrededor de los cuales se desarrolló la organización del poder sobre la vida. El establecimiento, durante la edad clásica, de esa gran tecnología de doble faz -anatómica y biológica, individualizante y específicante, vuelta hacia las realizaciones del cuerpo y atenta a los procesos de la vida- caracteriza un poder cuya más alta función no es ya matar sino invadir la vida enteramente" (Foucault, 1976:168).

Por lo tanto, el poder sobre la vida se extiende desde toda esa serie de procedimientos, mecanismos y técnicas que Foucault estudiara en Vigilar y castigar hasta toda esa serie de mecanismos que constituyen el segundo polo que se puede llamar estrictamente biopolítico. El primero de estos polos devendrá cabalmente biopolítico en el momento en que deje de tomar al cuerpo como una máquina física y empiece a tomarlo, para decirlo con Cuvier, como una individualidad orgánico-funcional, cuando pase de la anátomo-física a la anátomo-fisiología. Desde este punto de vista, todo el poder disciplinario no es sino un poder de hacer funcionar correctamente, un poder de corregir las dis-funcionalidades, de re-funcionalizar el organismo individual y de modo más elemental un poder de organizar (funcionalmente) un cuerpo.

Deleuze y Guattari dirían que es un poder cuya operación elemental es hacer del cuerpo un organismo, una organización orgánica de órganos (1980:163), un poder de producir un cuerpo orgánico-funcional para asegurar la ecuación político-económica entre docilidad y utilidad, es decir, una tecnología que "impone formas, funciones, uniones, organizaciones dominantes y jerarquizadas, transcendencias organizadas para extraer de él [el cuerpo] un trabajo útil" (1980:164).

En contraste, el segundo polo trabaja en la dimensión de esos otros dos fenómenos que emergieron posteriormente y sobre todo a partir de la transformación-Darwin: el medio y la población. Tiene como objetivo la gestión de la vida pero no ya en el sentido de la orga- 
nización del cuerpo, sino de regulación, aseguración, optimización y mejoramiento de los procesos biológicos de conjunto que sólo existen al nivel de una población, de la descendencia y de la especie. Esquemáticamente: si desde Darwin se sabía que la vida evoluciona y que en esa evolución el organismo podía modificarse por la presión de la selección en un medio dado sobre las poblaciones, se puede decir que a partir de entonces la biopolítica se situará en esa malla donde se entrecruzan las políticas de acondicionamiento del medio y las políticas de selección con todos sus efectos reguladores y aseguradores sobre las poblaciones y los organismos.

Incubada en los mecanismos de una Polizeiwiessenschaft que busca aumentar la vida de la población como forma de aumentar la fuerza de los Estados; germinada en las medidas de cierto higienismo y urbanismo que buscan hacer de lo biológico una materia de sus cálculos a partir de la regulación y mejoramiento de las condiciones de vida (los flujos de aire, agua, desechos, alimentos, etc.); la biopolítica se expandió a partir del cruce con el saber biológico evolucionista en los mecanismo reguladores, securitarios y racistas que buscan mejorar la vida y defenderla de si misma, horizonte en el que el dispositivo del racismo biológico de Estado (y el nazismo) pudo aparecer como una de sus formas paradigmáticas.

Esta congruencia entre estos dos polos en los que se desarrolló el poder sobre la vida y lo que podríamos ver también como dos polos (cuveriano y darwiniano) del saber biológico moderno no supone, sin embargo, pensar en términos de causalidad. Ni Cuvier, ni Darwin son 'los padres' de ese biopoder, pero tampoco son meros epifenómenos de éste, sus 'vástagos'. Lo que hay entre esos estratos de saber y los dispositivos de poder es una relación de exterioridad y presuposición mutua. Si bien, las relaciones de poder tienen una preeminencia sobre los estratos de saber, éstos no son una mera consecuencia de aquéllas. Entre ambos existe una relación de mutua retroalimentación: el desarrollo de las tecnologías de poder constituye objetos para nuevas formas de saber y éstos vehiculizan nuevos efectos de poder tanto como permiten el desarrollo ulterior de las primeras. De modo absolutamente simplificado pero gráfico podríamos decir que fue en el circuito de las instituciones disciplinarias y en las oficinas de Estado donde nacieron la individualidad orgánico-funcional y la población, y donde se posicionaron como objeto de un nuevo saber biológico que a su vez los fijó y permitió que se ejerzan sobre ellos inéditas técnicas políticas de dominación.

En ese sentido podríamos parafrasear libremente a Foucault y decir: se pretenden hacer historias de la biopolítica no sólo en el XVIII sino incluso en la antigüedad, pero no se advierte que la biopolítica no existía por la sencilla razón de que la vida misma no existía. En efecto la Vida y los fenómenos asociados a ella sólo fueron visibles y enunciables para el saber occidental tras la transformación radical que supuso el ordenamiento de la episteme moderna y el nacimiento de la biología. La biopolítica, en tanto que disposición de saberpoder, no es independiente de esta transformación. Más bien, puede decirse que la biopolítica es íntegramente dependiente, epistémica y ontológicamente, de los enunciados biológicos que afirmen lo que la vida es, en qué consiste, cuáles son sus umbrales, y de los mecanismos que la biología pone a disposición para intervenir en los procesos biológicos a fin de alcanzar sus objetivos, la regulación, mejoramiento y optimización de la vida y la explotación de su potencia. Con ello no pretendemos - o no pretendemos solamente - decir que la biopolítica sea un fenómeno que deba circunscribirse históricamente a la modernidad y cuya lógica 
deba emparentarse con el despunte del capitalismo ${ }^{2}$, sino que la transformación epistémica señalada y la consecuente emergencia de la Vida como dimensión semitrascendental son conditio sine qua non de lo que Foucault llamara el "umbral de modernidad biológica" y por lo tanto de la configuración de las tecnologías de poder biopolíticas.

En efecto, a partir del nacimiento de la moderna biología ésta no cesó de recortar alrededor de la vida nuevos campos de objetos que le permitieron a la vida constituirse como correlato privilegiado de los mecanismos modernos de poder. Las técnicas biopolíticas participan de este mismo movimiento de constante re-definición de la vida, ya que no se enfrentan a una vida que existe más allá de las formaciones históricas de saber-poder, sino que ordenan, normalizan, regulan, aseguran una vida producida por esas mismas técnicas de saber y de poder. Así, cuando hablamos de vida, se trata de una vida correlativa al saber y al poder y que por consiguiente carece de estatuto ontológico, o más bien, de una vida cuyo estatuto ontológico no es más que su modo histórico (ergo producido) de ser, una vida que es indeterminada y abierta a determinaciones y normalizaciones.

En consecuencia, hacia fines del siglo XVIII no se alcanza sólo el umbral de las condiciones de existencia de una biología moderna, sino análogamente el umbral de la modernidad biopolítica. Si la biopolítica designa la entrada de la vida en los cálculos del saber y del poder, la biología moderna, de la cual Foucault había intentado reconstruir su nacimiento en Las palabras y las cosas, designa el umbral a partir del cual unas tecnologías de poder han logrado constituir un saber relativo a la vida que incrementará su dominio y su eficacia.

Así, la tan celebrada frase de La voluntad de saber sobre la diferencia entre la existencia política aristotélica y la propiamente bio-política sólo encuentra en este modo radical de historizar un principio de inteligibilidad ${ }^{3}$. La frase implica que el concepto de vida correspondiente a la biopolítica no puede ser buscado en la noción aristotélica con sus divisiones y niveles y a la vez tampoco en la noción de la taxonomía de la Historia Natural de la época clásica, simple categoría dentro del cuadro de todos los seres. Ni arche, ni arcano del poder, el bíos de la biopolítica sólo puede ser pensado en el modo de ser de su positividad histórica, es decir, en relación a la moderna noción que unifica la Vida en esa invisible unidad focal más allá de toda representación (Ojakangas, 2005:5-28), en esa fuerza continua que más allá de los seres les confiere su existencia a la vez que los expone a la muerte, es decir: la biopolítica debe pensarse en conjunto con la transformación que designan los nombres de Lamarck, Cuvier, Bichat y luego, por su puesto, Darwin y el evolucionismo.

\section{Ars y Scientia}

Incluso si quisiéramos desplegar la primera periodización foucaultiana y nos desplazáramos hacia el trip grecorromano de sus últimos libros y cursos, podríamos decir que antes

2 Cosa que por otra parte Foucault afirma sin tapujos: "Ese bio-poder fue, a no dudarlo, un elemento indispensable en el desarrollo del capitalismo; éste no pudo afirmarse sino al precio de la inserción controlada de los cuerpos en el aparato de producción y mediante un ajuste de los fenómenos de población a los procesos económicos." (Foucault, 1976:170).

3 "Durante milenios, el hombre siguió siendo lo que era para Aristóteles: un animal viviente y además capaz de una existencia política; el hombre moderno es un animal en cuya política está puesta en entredicho su vida de ser viviente" (Foucault, 1976:174). 
del umbral de modernidad biológica a lo sumo se puede hablar de un arte de la vida, pero difícilmente de una ciencia biológica. Encontraríamos allí otro umbral, no el de los cortes epistémicos, sino el que surge del contraste entre ars y scientia. Y allí la ruptura aparece de modo más evidente en tanto las modernas ciencias de la vida asociadas a la biopolítica producen algo totalmente inverso a las artes de vivir de la antigüedad grecorromana. Foucault ha estudiado estas artes de la existencia, donde precisamente vamos a encontrar el bíos pero no como objeto de una disciplina científica y una tecnología de poder sino de una práctica de construcción de sí. Se trata del bíos no como objeto de una biopolítica sino como objeto de una estética de la existencia, de un procedimiento meditado de existencia, de una técnica del vivir, es decir de la tekhne tou biou que definió de distintos modos el centro de la filosofía desde los cínicos por lo menos hasta el ascetismo monacal (Foucault, 2001).

Para aclarar más nuestro punto de vista puede concebirse un paralelo entre las dos formas de relación con el bíos y las diferencia que Foucault propusiera (aún cuando luego la abandonara) entre una ars erotica y una scientia sexualis en La voluntad de saber o también, siguiendo Rerwriting the soul de Ian Hacking, entre los dos modos de la memoria según un arte memorativa y las modernas ciencias de la memoria (Hacking, 1995). En los tres casos, de un lado tenemos una verdadera tekhne, una ascesis, una práctica y del otro una ciencia, un discurso cuya producción esta regulada y que produce conocimiento disciplinado sobre un objeto al que a la vez constituye qua objeto y al que dispone como campo de emergencia de nuevos conocimientos según unas técnicas de saber específicas.

Para remontarnos hasta el punto de divergencia entre ars y scientia en los tres casos, perfectamente podríamos seguir la indicación de Foucault: "Nuestra civilización, a primera vista al menos, no posee ninguna ars erotica. Como desquite, es sin duda la única en practicar una scientia sexualis. O mejor: en haber desarrollado durante siglos, para decir la verdad del sexo, procedimientos que en lo esencial corresponden a una forma de saber rigurosamente opuesta al arte de las iniciaciones (...): se trata de la confesión” (1976:73) En la Hermenéutica del sujeto (2001), el curso de 1981, encontraremos el mismo desplazamiento: desde el arte de vivir a la hermenéutica de la carne. Desde la tekhne tou biou con sus modalidades heterogéneas en el mundo grecorromano y el cristianismo primitivo a la observación, el desciframiento y la exposición de la verdad de uno mismo: del cuidado al conocimiento.

En ambos esquemas (sexualidad y bíos) encontramos el modelo de una ars y una scientia y como antecedente de esta última a la pastoral cristiana, es decir esa tecnología de poder que ha atado de modo inconmovible cierto modo de extracción, producción y registro de la verdad y el funcionamiento de toda una serie de mecanismos de control y procedimientos de dominación ${ }^{4}$. Quizá es en esta tecnología que pueda situarse ese quiebre a partir del cual el poder no cesará de preguntar, de indagar, de registrar, lo que lo llevará a institucionalizar la investigación de la verdad, a recompensarla y profesionalizarla bajo la forma de un saber científico. Así la producción de verdad se convertirá con ella y para todo Occidente en un elemento quizá tanto o más decisivo que la producción de riqueza y al mismo tiempo se convertirá en un motor no sólo de la misma producción de riqueza sino de la dominación. La verdad hace ley y norma y por lo tanto empuja efectos propios de poder. Como decía

4 Foucault dedica varias clases del curso de 1978-1979 a esta idea de gobierno y su relación con la pastoral (2004:139-220). Se puede confrontar también la lectura de Agamben en El reino y la gloria (2008a:193-252). 
Foucault: "Después de todo, somos juzgados, condenados, clasificados, obligados a cumplir tareas, destinados a cierta manera de vivir o a cierta manera de morir, en función de discursos verdaderos que llevan consigo efectos específicos de poder" (Foucault, 1997:30).

La confesión tal vez pueda ser señalada como la primera forma de incardinación del poder sobre la vida no en los términos de una técnica de la existencia, sino en los de una tecnología de poder en el sentido antes descrito y que se ocupa del tiempo de vida y de su salvación bajo el modo de la producción de un discurso ininterrumpido cuyo objetivo es un control al que nada debe escapar ${ }^{5}$. Pero, sin embargo, es recién a fines del siglo XVII, cuando se producirá la transformación decisiva de este poder pastoral: el paso de la confesión al $e^{e x a m e n}{ }^{6}$. A partir de XVIII el examen como técnica de producción de la verdad estará en el origen de la sociología, las 'ciencias psi', la criminología, la estadística y la demografía, la medicina, la pedagogía, etc., esos saberes que nacieron en conexión directa con la formación del poder disciplinario, en el doblez de las ciencias de la Vida, el Lenguaje y el Trabajo en los inicios de la sociedad capitalista.

De un polo al otro, una gran maquinaria de registro de lo insignificante, de lo individual y lo masivo transformará el viejo confesante en un asunto científico y estadístico: en un caso que a la vez constituirá un objeto para un conocimiento y una presa para un poder, en una distribución, en una curva, una zona de una curva, que puede ser administrada (Foucault, 1975:196-197 y 2004a:80). Allí tendremos el pasaje entre el bíos como objeto de un técnica de constitución de sí, confesión mediante, al bíos como objeto de un saber y un poder biopolíticos.

Ésta máquina abrirá dos posibilidades correlativas: la constitución del individuo como objeto de saber, como objeto analizable bajo la mirada de un saber permanente (Foucault, 1975:195), polo que podríamos llamar específicamente disciplinario o anátomo-político (singulatim); y por otra parte (como lo decía Foucault ya en Vigilar y castigar y sin usar la noción de biopolítica) "la constitución de un sistema comparativo que permite la medida de fenómenos globales, (...) la estimación de las desviaciones de los individuos unos respecto de otros, y su distribución en una 'población'” (1975:195), polo que podríamos llamar propiamente biopolítico (omnes).

En ese sentido, Foucault afirmaba que las "técnicas disciplinarias de poder referidas al cuerpo habían no sólo provocado una acumulación de saber sino puesto de relieve dominios posibles de saber" (1997:172). En el corazón de la empresa disciplinaria la maquinaria de registro supura un nuevo saber, un saber del cuerpo no ya puramente mecánico, sino un saber sobre el cuerpo en tanto organismo y a la vez un saber que descubre o más bien cristaliza ese fenómeno que surge frente a la mirada disciplinaria, el fenómeno global de la población. Uno y otro señalan el umbral de modernidad biológica y los dos polos del poder sobre la vida, el cuerpo individual y el cuerpo-especie. Pero sobre todo es este último el que señala

5 Implica por ello mismo una forma de sujeción subjetiva mediada por una autoridad que se arroga el poder de extraer pero también de obligar a producir "verdad" al sujeto. Luego trasciende el ámbito de la Iglesia y se convierte en una forma jurídica (confesión judicial). Sobre esta conversión jurídica durante la edad media, ver el análisis de la noción de indagación (enquête) en las conferencias La verdad y las formas jurídicas (1994b:538[1973]).

6 Sobre la importancia del examen en la historia de los regimenes de producción de la verdad ver también las conferencias de 1973 (1994b:538[1973]) y sobre el examen como dispositivo central de la tecnología disciplinaria, toda la tercera parte de Vigilar y castigar y sobre todo el parágrafo homónimo (1975:189). 
el umbral de modernidad biopolítica, ese que las sociedades occidentales atravesaron cuando incluyeron a la especie en sus cálculos políticos (Foucault, 1976:173).

La noción de especie es en este sentido determinante para Foucault, ya que el umbral mismo puede situarse en el pasaje que va desde le genre humain a la espèce humaine (Foucault, 2004a:101), desde las raíces del primero (gen) que refieren al jus gentium y por lo tanto al dominio del poder soberano a la noción de especie donde el principio de pertenencia común es proporcionado por las propiedades biológicas compartidas. Así, cuando el género humano aparece como especie entre las otras especies vivientes el hombre se presenta en su profundo arraigo biológico. Pero debe tenerse en cuenta que no se trata ya de la especie en los términos del saber taxonómico, sino en tanto constituye un fenómeno estrictamente biológico. En ese sentido dice Foucault que no se trata de la reducción a 'rasgos específicos' que hacen los naturalistas, sino de esos dos polos que son el individuo y la población (Foucault, 1975:195). Fue la población y no la especie (diferencia específica), en su globalidad y según su distribución, como elaboración estadística a partir de la dispersión de las variaciones individuales (en el tiempo) la que vino a definir a partir del horizonte abierto por Cuvier, señalado por el nacimiento del continuum de la Vida y por el borramiento de los umbrales de la Historia Natural, un nuevo nivel de realidad, un umbral epistemológico y ontológico, el umbral de lo propiamente biológico.

El cuerpo-especie al que se dirige la biopolítica no es el de la Historia natural, es decir, la especie como preocupación nominalista, como correcta designación, sino el cuerpo que surgió cuando la organización y la función dieron lugar a una (dis)continuidad de lo biológico y sobre todo el cuerpo estadístico que surgió con Darwin. Así, si bien, fue Linneo el primero en poner al hombre como especie entre otras especies y en emparentarlo con el mono, ese parentesco y esa especie no eran más que una colección de seres idénticos pertenecientes a una misma clase a partir de su carácter visible o una serie de copias correspondientes a un Modelo, pero no una realidad unitaria, global y a la vez individualizable. Así, que se cruce el umbral de la biopolítica a partir del momento que el hombre empieza a ser tratado como una especie e introducido como tal en los cálculos de la política, significa a partir del momento en que empieza ser observado, regulado, asegurado como conjunto orgánico funcional y distribución estadística, en tanto fenómeno global o caso individual de una población.

Desde el punto de vista de la inmanencia mutua entre saber y poder, efectivamente, hay biopolítica desde el mismo momento en que es pensable una scientia de la vida: hay biopolítica desde que hay una bio-logía - e inversamente.

\section{Salut: de la salvación a la salud}

Desde la pastoral cristiana a la biopolítica moderna, el registro y el examen permanente son elementos necesarios del gobierno. La tecnología gubernamental, supone siempre una máquina de registro, pero ésta varía históricamente, del gobierno de las almas al de los fenómenos biológicos de una población, desde el confesionario al laboratorio antropométrico: de la confesión al examen. En términos del gobierno de la vida esta transformación significó el paso del dominio religioso de la salvación ultramundana a la gestión administrativa de la salud del organismo y de la población, pero también y dentro de la misma semántica, a la Salut publique y a la Rassenhygiene. 
En Fe y saber, Derrida (1996) ha analizado la relación entre la esfera de la religión y la de la tele-tecno-ciencia, mostrando cómo entre ambas existe un nexo de implicación profundo que se desplaza todo a lo largo de la semántica de la salvación (lo sano, lo santo, lo sagrado, lo salvo, lo indemne, lo inmune, etc.). Según la genealogía foucaultiana hay una cadena no sólo semántica sino una gubernamental que va (no linealmente) desde la salvación de la grey a la salud del cuerpo y la población, de la nación o de la raza; desde el gobierno pastoral de tradición judeo-cristiano (pasando por la razón de estado y la polzei) a la biopolítica moderna (Foucault, 2004a).

Según los estudios de Foucault, en al antigüedad grecorromana la cuestión del gobierno e incluso la del pastor no era desconocida, pero es radicalmente distinta de la cuestión cristiana del pastorado como modelo paradigmático del gobierno, y a la vez de la cuestión del gobierno tal como se configurará tras la Reforma y la Contrarreforma (Foucault, 2004a:160176). Estas últimas dieron al gobierno una autoridad antes imposible sobre la vida material y cotidiana de los individuos (particularmente sobre sus conductas) que finalmente desbordó todo el ámbito eclesial, al punto que algo así como una razón gubernamental mucho más general desplazó al pastorado cristiano. En efecto, el gobierno tuvo su explosión entre el siglo XVI y el XVIII, en plena época clásica. Ésta, verdadera "era de los gobiernos" (Foucault, 2004a:268), estuvo signada por la obsesión del gobierno de los niños, de los locos, de los enfermos, de los criminales, los degenerados, etc. (Foucault, 1999) y fue precisamente esta techne technon, en el proceso progresivo de gubernamentalización que se extiende desde el siglo II de nuestra era hasta el siglo XVIII, el que fue recortando sobre lo real y derivando de la semántica de la salvación las cuestiones de la de la salud, la higiene, la Vida y sus fenómenos.

Fue efectivamente la pastoral la que tomó por vez primera vez la vida individual y de la grey (y no el territorio) como blanco de poder y fuente de verdad. Así, Foucault mismo habría dado las pistas de una prehistoria de la bio-política que tendría sus orígenes en los egipcios y asirios pasando por el judaísmo hasta su desarrollo creciente en los primeros siglos de la pastoral cristina, pero no puede confundirse esta prehistoria del gobierno de la grey con la moderna biopolítica y menos aún suponer una linealidad sin rupturas entre ellas. La pastoral es el antecedente de la "unión demoníaca" del gobierno moderno de omnes et singulatim, pero el proceso de gubernamentalización está lleno de fracturas y entre ellas la época clásica, con el paso de la confesión al examen y de lo eclesiástico a lo político, fue determinante.

En efecto, el gobierno pastoral supone un mundo enteramente finalista y antropocéntrico, una naturaleza poblada de prodigios, maravillas y signos, un Mundo-Libro, lleno de cifras y designios divinos por decodificar. Un mundo tal como lo fue hasta el renacimiento en el que las signaturas constituían la forma manifiesta de un gobierno pastoral de Dios sobre el mundo. Un mundo, cuyo ocaso fue la época clásica: "Exactamente entre 1580 y 1650, la fundación misma de la episteme clásica (...) corresponde a (...) una desgubernamentalización del cosmos" (Foucault, 2004a:275). En la época clásica se quebró el continuo teológico cosmológico que iba de Dios al padre de familia pasando por el soberano y se desplazó la cuestión desde el gobierno pastoral eclesiástico a la búsqueda de una forma de gobierno que sea específica al ejercicio del poder político. 
Se dio así una gubernamentalización de la soberanía y de lo político en el mismo momento en que Dios dejó de gobernar el mundo de modo pastoral para regirlo soberanamente según principios generales. El cosmos dejó de estar sometido a un gobierno divino, poblado de signaturas divinas, para transformarse en una naturaleza ordenada según principios matemáticos y clasificatorios (mathesis universalis) ${ }^{7}$. El mundo-Libro dio lugar a un mundo-Fichero que abrió la cuestión de la tarea específica del soberano que no puede ser ya la de Dios respecto a la naturaleza ni la del pastor respecto a su grey. A partir de entonces tuvo lugar el desbloqueo político del gobierno y la vieja cuestión de la soberanía fue parasitada por él. ${ }^{8}$

En ese cruce, justo cuando Luis XIV dice "el Estado soy yo" (y designa a Colbert para la administración de las finanzas y el comercio) soberanía y gobierno se funden, o más bien la primera se gubernamentaliza, a la vez que el gobierno como tecnología de poder se desmarca de su inscripción religiosa y puede generalizarse en todos los dominios seculares. Entonces, se dieron las condiciones de posibilidad del despegue político del gobierno y de la secularización de sus fines desde la salvación a la salud, la salubridad, la sanidad, la vitalidad, el bien-estar, etc. es decir, la naciente semántica de la vida, de la vida y su mejoramiento.

\section{Respiran}

En esta época de los gobiernos y de los cuadros, veremos operar todas unas estrategias de poder que por el juego incesante y ciego de sus técnicas, sin tener un saber disciplinar sobre la vida, la sitiarán y la harán objeto para un saber posible, la naciente biología. Por eso, si bien más tarde o más temprano irrumpirá la Vida tanto en el cuadro del naturalista como en el cuadro del panóptico, el tempo de esta doble irrupción no coincide.

Según narra P. Kropotkin al inicio de su Memorias de un revolucionario (1902) y recupera Foucault (siguiendo una indicación de G. Canguilhem) el Gran Duque Miguel Nikolaevich de Rusia, hijo del Zar Nicolas I, ante el cual se había hecho maniobrar a las tropas en "un desfile tan ordenado y alineado que los soldados parecían juguetes" habría dicho

7 Los principia naturae ponen de manifiesto la configuración clásica del saber que va desde la astronomía de Copérnico y la física de Galileo a de la gramática de Port Royal y la Historia natural.

8 Es interesante recordar que en El Reino y la Gloria (2008a) es precisamente esta ruptura la que Agamben pone en cuestión a partir de su genealogía teológica. Lo que además evidencia la distancia que existe entre el método arqueológico-genealógico foucaultiano y la arqueología de las signaturas tal cual es comprendida por el italiano (2008b). Para Agamben se trata de desplazar la cuestión desde el archivo foucaultiano al archivo teológico para sustentar su hipótesis según la cual la genealogía de las instituciones políticas modernos debe trazarse a partir de los paradigmas de la teología, ya que, según la máxima de Schmitt "todos los conceptos significativos de la moderna teoría del Estado son conceptos teológicos secularizados”. En Homo Sacer I se trataba de partir de la teología política para comprender la institución moderna de la soberanía y en El reino y la gloria se trata de comprender a partir de la teología económica la gubernamentalidad moderna. En un caso como en el otro, la teología sería la pre-historia siempre presente y actual en la historia, lo arcaico que coincide con lo contemporáneo. Este desplazamiento teológico de la cuestión es lo que le permite a Agamben criticar los límites de la genealogía foucaultiana del gobierno. Pero en esta misma crítica lo que Agamben pone en cuestión es el proyecto mismo de la genealogía y la arqueología foucaultianas. Por ello, más allá de sus referencias benjaminianas y foucaultianas, el arcano agambeniano se parece siempre a un olvido fundamental y por lo tanto se emparenta más con la destrucción heideggeriana de la metafísica que con la ontología histórica del presente de Foucault. 
tras una largo análisis de la maniobra: "Está bien, pero respiran” (Foucault, 1975:193). Detectaba justamente algo que no era evidente para el saber de la época clásica y que hacía fallar la muestra ostentosa del poder taxonómico. Algo que no conoce pero le preocupa, algo que no estaba previsto y desborda el cuadro: esos cuerpos respiran, funcionan en ciertas condiciones de existencia, viven y mueren, oponen al ordenamiento taxonómico-militar las condiciones de funcionamiento propias de un organismo (Foucault, 1975:160).

La (dis)función es el cuerpo, no sólo lo que respira y jadea, sino lo que se tambalea, lo que cojea y por lo tanto falla el cuadro, lo que duele, el milagro del equilibrio y de su permanente perdida, la desviación. Por ello la eliminación de sus disfunciones, la corrección de su funcionamiento, su ortopedia o su organización, el control de la desviación, están en el corazón de la queja y del sueño anátomo-político del Duque. Éste se sitúa en relación al cuadro militar en la misma posición en la que Lamarck y Cuvier en relación al cuadro naturalista.

El saber que efectivamente nace allí, en esa época, en los hospitales, en las escuelas militares, en las oficinas de estadística y que va más allá de todo lo que se puede englobar con el nombre de biología, no formula un concepto de vida, sino que la fabrica constantemente definiendo y redefiniendo los procesos vitales, su extensión, su continuidad, sus rupturas, su campo de objetos y sus límites, sitiándola como blanco de un poder, de un bio-poder posible.

En un juego de doble vuelta entre saber y poder, en el intersticio entre uno y otro " $e l$ hombre occidental aprende poco a poco en qué consiste ser una especie viviente en un mundo viviente, tener un cuerpo, condiciones de existencia, probabilidades de vida, salud individual o colectiva, fuerzas que es posible modificar y un espacio donde repartirlas de manera óptima" (Foucault,1976:172), es decir: aprende a concebirse a sí mismo como ser vivo, a ser una existencia biológica, a que la vida sea su más profundo modo de ser; aprende a reconocer una fuerza que bulle en su cuerpo y lo expone a la muerte y finalmente confirma que su ser no es más que el no-ser de la Vida. Aprende qué significa ser un vivi-ente, que es a la vez es objeto de todo un saber y un poder antes impensados.

$\mathrm{Si}$ arqueológicamente es posible situar la ruptura que marcó el nacimiento de la Vida, desde el punto de vista genealógico no hay más que multiplicidad de fuerzas, rupturas diseminadas por todos lados, una capilaridad movediza, pero es en esa misma dispersión en la que puede aparecer la regularidad que señala el saber y sus cortes. Entre ambos, el umbral de modernidad biológica: "por primera vez en la historia, sin duda, lo biológico se refleja en lo político; el hecho de vivir (...) pasa en parte al campo de control del saber y de intervención del poder" (Foucault, 1976:172). Es ese umbral el que señala la anécdota del Duque Miguel: la rotura del cuadro disciplinario del mismo modo que la emergencia de la Vida supuso la rotura del cuadro taxonómico de la Historia Natural.

Efectivamente el 'cuadro' es para el siglo XVIII a la vez una empresa política y una empresa científica, una técnica de poder y un procedimiento de saber, en ambos casos permite organizar lo múltiple, dominarlo, imponerle un orden. No se trata de una simple semejanza: "la constitución de 'cuadros' ha sido uno de los grandes problemas de la tecnología científica, política y económica del siglo XVIII” (Foucault, 1975:152) presente en la clasificación de los seres vivos, en el control de la circulación de las mercancías, en la normalización de los hombres, etc. Aún más, como reconoce Foucault "la primera de las grandes operaciones de la disciplina es (...) la constitución de 'cuadros vivos' que trasfor- 
man las multitudes confusas, inútiles o peligrosas, en multiplicidades ordenadas" (Foucault, 1975:152). El gabinete del naturalista, el herbolario, el jardín botánico, donde la naturaleza era ordenada, cuadriculada y puesta a disposición de una mirada atenta a las formas y detalles de las superficies visibles, eran las formas institucionales del saber taxonómico, pero también lo eran otros espacios menos asépticos que comenzaban a configurase: los nacientes hospitales, las cárceles, las escuelas, etc.: la forma general del panóptico, esa paradigmática máquina de ordenación de lo visible.

De allí que haya sido condición de posibilidad de la clínica moderna la organización del hospital como aparato de examinar, como régimen de visibilidad que permitió el desbloqueo epistemológico de la medicina a fines del siglo XVIII (Foucault, 1963:190). El panóptico de hecho tiene un poco de jardín botánico y un poco de laboratorio (Foucault, 1975:208). Jardín en tanto allí se establecen las diferencias, se observan los síntomas y las conductas, los efectos del contagio, se registran las características singulares; laboratorio en tanto máquina de hacer experiencias, de modificar el comportamiento, de encauzar la conducta, donde se experimenta y se verifican efectos.

Esa es la situación del panóptico hacia el final del XVIII en cuyo seno se están formando técnicas científicas que responden a cuestiones políticas y económicas novedosas y que a su vez están fijando nuevos blancos para un saber que ya no se limita a denominar, a decir lo visible, sino que empieza a examinar. El examen como técnica central del panóptico hace la diferencia con el cuadro del naturalista: no se trata de la caracterización del individuo y su reducción específica, sino de mantenerlo en sus rasgos singulares frente a una mirada permanente (que busca la profundidad mas allá de lo visible) y de someterlo a un sistema comparativo que permite la medida de fenómenos de población: "Mientras que la taxonomía natural se sitúa sobre el eje que va del carácter a la categoría, la táctica disciplinaria se sitúa sobre el eje que une lo singular con lo múltiple" y tiene por función "tratar la multiplicidad por sí misma, distribuirla y obtener de ella el mayor número de efectos posibles" (Foucault, 1975:152).

Omnes et singulatim, lo singular y lo múltiple, individualidad orgánico-funcional y población serán los dos polos del examen y del panóptico. El panóptico, entre la época de la Mathesis y la del Hombre cuenta otra historia del saber moderno y ésta a la vez nos permite entender el funcionamiento del primero. Ya lo decía Foucault el nacimiento del saber moderno "hay que buscarlo en esos archivos de poca gloria donde se elaboró el juego moderno de las coerciones sobre cuerpos, gestos, comportamientos" (Foucault, 1975:196)9.

Cuando el sueño de la taxonomía humana, de la arquitectura disciplinaria y de la anatomía de papel milimétrico se ensoberbecía en su delirante poder, el Duque hacía sonar su descontento que socavaba la fantasía disciplinaria: "pero respiran". Sintagma quejumbroso que extraía los lubricantes de esa gran maquinaria y la disecaba. Toda la época clásica se estremecía frente al espesor de esa respiración húmeda, de ese hálito, de ese jadeo, y de ese estertor. No podía ser de otra manera. Para la época clásica, donde tuvo lugar el descubri-

9 Ese es el desplazamiento que supone la genealogía de Vigilar y Castigar (1975) respecto a la arqueología de Las Palabras y las cosas (1966). En este sentido puede leerse como momento de pasaje la serie de conferencias La verdad y las formas jurídicas dictadas en Rio de Janeiro en 1973 (1994:538), donde de hacho toda la transformación epistémico-política de la modernidad pivotea en torno a la técnica científica y jurídico-política del examen. 
miento del cuerpo como objeto y blanco de poder, había allí algo del orden de lo impensable. En los límites de la estructura mecánica se estaba formando un nuevo fenómeno capaz de vivir y susceptible de morir: el cuerpo natural, el cuerpo-organismo, anátomo-biológico. Luego, en el intento de explicar lo vivo dentro de una mecánica general se lo hará en términos de función, lo que dará lugar al nacimiento de la biología y operará una transformación radical en los modos de pensar lo vivo como también en las formas biopolíticas de ponerlo en juego.

Según Foucault, no lo olvidemos, era en Descartes en donde debía buscarse la procedencia anátomo-metafísica del cuerpo analizable de las disciplinas. ¿Qué es el cuerpo de las disciplinas sino el cuerpo de Descartes, y qué es éste (como el que quiere Duque) sino un cadáver? "Consideraba, (...) que tenía una cara, manos, brazos y toda esta máquina compuesta de huesos y carne, como se ve en un cadáver, la cual designaba con el nombre de cuerpo" (Descartes, 1641:127) A lo que habría que agregar un cadáver visible. Para él como para el naturalista conocer el cuerpo es señalar su estructura visible y desde este punto de vista la vida no hace la diferencia. El cuerpo inteligible que nombra Descartes en ese primer pensamiento es un mecanismo, un conjunto de palancas y poleas que hacen un autómata. Es este registro cartesiano del cuerpo el que los médicos, biólogos e higienistas vendrán a desbordar con una verdadera "reducción funcional del cuerpo" (Foucault, 1975:169).

Paralelamente otro registro, técnico-político, constituido por reglamentos (militares, escolares, hospitalarios) y por procedimientos empíricos, hacía del cuerpo algo no sólo inteligible sino, utilizable y sumiso. Cuerpo dócil, máquina, autómata, cadáver: ese es el registro en el que la anatomopolítica de la época clásica piensa, analiza, y ordena el cuerpo. Un cuerpo que ha sido descompuesto analíticamente y despojado de sus marcas, de los signos (divinos y demoniacos) con los que contaba. Ha perdido incluso su unidad. Descompuesto en partes es objeto de una mecánica política que trabaja sobre sus movimientos, gestos, actitudes, fuerzas y que controla minuciosamente sus operaciones en el tiempo y el espacio. Pero ese cuerpo al ser puesto en juego de una forma cada vez más constante y profunda en los nuevos mecanismos de poder y saber, secretará en el corazón mismo de la época clásica una sustancia impensable para la Historia Natural, un cuerpo orgánico y funcional, viviente.

Paralelamente, ese mismo cuerpo descompuesto microfísicamente, al ser recompuesto en una multiplicidad, traerá como resultado, no el conjunto de la mera especie taxonómica sino una "población", un fenómeno global irreductible a la serie de individuos. Dará lugar a una realidad profunda e invisible cuyos efectos caracterizan a una multiplicidad en el orden de lo global. Hará posible concebir una continuidad más allá de los organismos individuales de la que está compuesta y a los que afecta en tanto pertenecen a una multiplicidad, a una realidad profunda y trans-orgánica: un continuum biológico.

Esta segunda transformación afectaba al problema técnico central de la infantería desde el XVII y luego de la explotación fabril capitalista: la composición de fuerzas, es decir, la necesidad de liberarse del modelo físico de la masa y de los cuerpos-signos para aprovechar la fuerza orgánica (Foucault, 1975:166). Se trataba de hacer útil a cada individuo y por ello era necesario inventar una maquinaria que no tuviera por principio la masa sino una geometría de segmentos divisibles cuya unidad de base fuera el soldado con su fusil o el obrero con su herramienta. Una exigencia nueva: construir una máquina cuyo efecto se llevará al máximo por la articulación concertada de las piezas elementales de que está compuesta. 
La disciplina no es simplemente un arte de distribuir cuerpos y extraer de ellos fuerza sino también de componer fuerzas. Se trata por lo tanto de la reducción funcional del cuerpo y de su articulación dentro de una multiplicidad o población.

El sueño físico y taxonómico de la disciplina se asoma, así, a su afuera: descubre que los cuerpos respiran, sudan, desfallecen, excrementan, se alimentan y se reproducen... que los cuerpos son organizaciones funcionales que tienen ciertas condiciones de existencia (Cuvier). Lo que no significa solamente que esos cuerpos forman una globalidad sometida a ciertos procesos de conjunto, sino que incluso en su individualidad están sometidos a procesos irreductibles al cadáver cartesiano o al sueño disciplinario: en el cuerpo hay algo de indomable, una fuerza que lo sobrepasa y que incluso lo expone a la muerte y que resiste desde su profundidad. Lo que la disconformidad del Duque descubre es que los cuerpos son más que un haz de movimientos de gestos descomponibles y combinables. Ese algo que respira es lo que provocará la necesidad de explicar lo vivo: "el comportamiento y sus exigencias orgánicas van a sustituir poco a poco la simple física del movimiento. El cuerpo, al que se pide ser dócil hasta en sus menores operaciones, opone y muestra las condiciones de funcionamiento propias de un organismo" (Foucault, 1975:160). Esas exigencias orgánicas, van a implicar de la mano de Lamarck una jerarquía de los caracteres y una subordinación funcional que alejará la mirada hacia la arquitectura profunda de los seres desde donde brota el hálito que la época clásica no consigue comprender. Esas condiciones de funcionamiento propias de un organismo constituirán pronto para Cuvier las condiciones de existencia, las cuales se integraran en un medio de vida (Darwin). Con ello la Vida, en su profundidad, invisible visible, habrá dispuesto una región de lo que existe.

En ese sentido, el poder disciplinario tiene como correlato una individualidad no sólo analítica y física sino, en sus límites, también una anátomo-fisiológica y una multiplicidad biológica. En el cruce, en la intersección no ya del cuerpo descompuesto y la serie (la gran máquina-de-cuerpos dóciles), sino en el cruce de las funciones orgánicas y la población va a venir a alojarse este nuevo poder que surge emparentado a la disciplina pero es irreductible al primero: la bio-política.

\section{Saber, poder, actualidad}

Finalmente, a través de este recorrido un tanto espinoso por los umbrales de la biopolítica podemos ver nacer los mismos elementos que surgen de un estudio arqueológico sobre el nacimiento de la vida tal como el que delineara Foucault a partir de Las palabras y las cosas: organismo, función, medio, población. Existe sin embargo una especie de defasaje entre el recorrido arqueológico y el genealógico. El primero permitía a Foucault afirmar que en la época clásica era inútil preguntarse por la biología y la vida, y por la vía genealógica vemos cómo en la misma época clásica la vida y sus fenómenos fueron adquiriendo progresivamente volumen en el juego de fuerzas de las instituciones disciplinarias. Fenómenos aún no formados como objetos del saber, pero si ya delineadas como blancos del poder. Es que la genealogía da cuenta de cómo se forman esas positividades que en la arqueología aparecían como producto de unas rupturas cuya historia se esfumaba.

La ruptura profunda en el régimen del discurso científico en la que la problemática de la Vida, y de forma paralela las del Trabajo y el Lenguaje (que delimitan la figura del Hombre) 
redistribuyeron el orden de la episteme clásica, fue a la vez condicionante y condicionada por la emergencia del bio-poder. El bíos de biopolítica no es, por tanto, sólo lo puesto en juego en unas relaciones de poder, sino lo producido y fijado por una técnicas de saber, lo que está en juego entre saber $y$ poder. En efecto, si en la modernidad occidental el poder pudo tomar como objeto a la vida, ello sucedió al calor de un saber que con sus técnicas aisló, fijó e hizo terreno de posible intervención a la Vida en y más allá de los seres vivientes. La vida, en este sentido, como la locura, la sexualidad, etc. no es una simple evidencia, es más bien una problematización o el producto de una serie de biologizaciones progresivas, no posee una esencia, sino que se ha construido históricamente a partir de una serie de relaciones de fuerzas, de articulaciones de saber y poder.

Intentar recomponer estos umbrales de la biopolítica no tiene un valor meramente erudito. Se trata de los prolegómenos de una escritura en dos sentidos a la vez. Uno que, a través de Foucault, nos lleva al pasado, al nacimiento de la Vida y de la política de la vida en la modernidad occidental. Otro, en el que por medio de ese desvío nos conduzca a la parte de lo actual en la biopolítica, a las transformaciones en los enunciados que describen la vida y a las prácticas que la producen tanto como a las técnicas que se encargan de su control hoy ${ }^{10}$. Sólo a partir de esa doble dirección nos parece posible un ejercicio de actualización del diagnóstico foucaultiano. Sólo sobre ese trasfondo, nos parece posible, mantener abierta la interrogación foucaultiana sobre la biopolítica.

En efecto, si la Vida moderna, dimensión semi-trascendental más allá de los seres, era el blanco de la biopolítica moderna; si organización, función, medio, población definían la regularidad en la dispersión de los enunciados científicos modernos sobre la vida, es valido interrogarnos: ¿cuáles son los enunciados que definen hoy los límites de lo vivo? ¿Cuáles las tecnologías políticas que toman a la vida por objeto? Sin dudas, el suelo a partir del cual era visible, enunciable, pero también normalizable y regulable la vida en la modernidad ha cambiado. Para comprender cómo opera y cuáles son los rasgos de la biopolítica de nuestro tiempo hay que interrogar, por lo tanto, los procesos que han afectado de modo decisivo el estrato del saber biológico contemporáneo, redefiniendo sus límites, sus técnicas y su objeto. Foucault preguntaba ya en los '70, al descubrir el vínculo entre la biología y las ciencias de la información: ¿una biología sin vida? Por lo menos, sin la Vida tal cual fue puesta en juego entre saber y poder modernos. En su lugar: genes, macromoléculas, información, mensajes, códigos, sistemas. Mantener abierta la interrogación foucaultiana, implica prestar atención a estas nuevas realidades y los interrogantes que nos proponen. Ese es el umbral de la biopolítica en el cual nos encontramos.

\section{Referencias}

Agamben, (1995): Homo Sacer I. El poder soberano y la nuda vida. Pre-Textos, Valencia, 1998.

- (2008a): El Reino y la Gloria. Una genealogía teológica de la economía y el gobierno, Adriana Hidalgo.

10 Ese es el sentido último de nuestra investigación. De ello nos hemos ocupado en otros escritos. (Sacchi, 2014; 2015) 
Deleuze, Gilles y Guattari, Félix (1980): Mil Mesetas. Capitalismo y esquizofrenia, Pretextos, Valencia, 2002.

Derrida, Jacques (1996): “Fe y Saber” en El siglo y el Perdón. Fe y Saber, Ed. de la Flor, Bs. As., 2003.

Descartes, Rene (1641): Meditaciones Metafísicas, Espasa-Calpe, Bs. As., 1937.

Foucault, Michel (1963): El nacimiento de la clínica, Siglo XXI, México, 1997.

- (1966): Las palabras y las cosas, Siglo XXI, España, 1984.

- (1975): Vigilar y castigar. Nacimiento de la prisión, Siglo XXI, México, 1997.

- (1976): Historia de la Sexualidad I. La voluntad de saber, Siglo XXI, Buenos Aires, 2002.

- (1981): Omnes et singulatim: hacia una crítica de la razón política, Conferencias en la Stanford University, 10-16 de octubre de 1979 en La vida de los hombres infames, Caronte, Bs. As., 1996.

- (1994a): Dits et écrits, tomo I, Paris, Gallimard, 2001.

- (1994b): Dits et écrits, tomo II, Paris, Gallimard, 2001.

- (1994c): Dits et écrits, tomo III, Paris, Gallimard, 2001.

- (1997): Defender la sociedad. Curso en el Collage de France (1975-1976):, FCE, Bs. As., 2000.

- (1999): Los Anormales. Curso en el Collège de France (1974-1975):, FCE., Bs. As., 2000.

- (2001): Hermenéutica del sujeto. Curso en el Collège de France (1981-1982):, FCE, Bs. As., 2002.

- (2004a): Seguridad, Territorio, Población. Curso en el Collège de France (1977-1978):, FCE, Bs. As., 2006.

- (2004b): Nacimiento de la biopolítica. Curso en el Collège de France (1978-1979): FCE, Bs. As., 2007.

Hacking, Ian (1995): Rewriting the Soul: Multiple Personality and the Sciences of Memory, Princeton University Press, Princeton.

Ojakangas, Mika (2005): “Impossible Dialogue on Bio-power. Agamben and Foucault” en Foucault Studies, n. 2, Mayo.

Paponi, M. Susana (1997): Michel Foucault. Historia: problematización del presente Biblos, Bs. As.

Sacchi, Emiliano (2015): “Biopolíticas postorgánicas: Biotecnología, plusvalía maquínica y biocapital" en Gaona y Zaretti (Comps.): Errancias: corporalidad, información, experiencia, CEFC, Neuquén, 2015. Disponible en: http://www.cefc.org.ar/index.php/ libro-digital-errancias

- (2014): “Actualidad y biopolítica. De la población a las moléculas” en Giavedoni J. y Campana, M. (comps.): Gobierno, Estado y control social, PEGES - UNR, Rosario, 2014. Disponible en:

https://www.academia.edu/6336924/Actualidad_y_biopol\%C3\%ADtica_de_la_ poblaci\%C3\%B3n_a_las_mol\%C3\%A9culas

- (2014): "Del munus común a la vida impersonal. Comunidad y biopolítica en R. Esposito” en Revista Internacional de Comunicación y Desarrollo (RICD):, Ed. Universidade de Santiago de Compostela, Santiago de Compostela, España. Vol. 2. Noviembre de 2014. Disponible en:

http://www.usc.es/revistas/index.php/ricd/article/view/2350/2471 
- (2014): "The biopolitical paradox: population and security mechanisms" en International Social Science Journal de UNESCO, ISSJ N 205/206, Blackwell \& UNESCO, Londres. Disponible en:

https://www.academia.edu/6336827/The_biopolitical_paradox_population_and_security_mechanisms

Sacchi, E. y Saidel, M. (2014): "De la biopolítica a la estética de la existencia: ¿hacia una política de la vida?" en Revista Revista El banquete de los dioses, no.3, Ed. Instituto de Investigaciones Gino Germani - UBA, Bs. As., Noviembre de 2014. Disponible en: http://www.banquetedelosdioses.com.ar/3/01_SacchiySaidel.pdf

Tarizzo, Davide (2010): La vita, un'invenzione recente, Laterza, Bari-Roma.

Veyne, Paul (2008):, Foucault, pensamiento y vida, Paidós, Barcelona. 
